\title{
POSYANDU DIGITAL DALAM MENGATASI ISU STUNTING DI RW 06 CIKUTRA
}

\author{
Muhamad Sabar ${ }^{1}$, Muchammad Naseer $^{2}$, Kristian Ismail $^{3}$ \\ Program Studi Teknik Informatika, Sekolah Tinggi Teknologi Bandung ${ }^{1,2,3}$ \\ m.sabar.sttb@gmail.com¹, naseer@ sttbandung.ac.id ${ }^{2}$, kris005@lipi.go.id ${ }^{3}$
}

\begin{abstract}
Abstrak
Pelayanan dengan menggunakan kertas dan berbasis elektornik memang memiliki dampak yang berbeda, selain memberikan kemudahan dan kecepatan, layanan dengan elektornik lebih digemari oleh generasi saat ini. Di RW 06 Cikutra kota Bandung, peneliti dengan paltform Google Sites, membuat website RW yang mengakomodir layanan warga, antara lain administrasi, posyandu, siskamling, hingga IKM.

Khusus pada layanan posyandu, tercantum info ketahanan pangan yang bisa membantu masyarakat dalam mencegah isu stunting. Selain memberikan informasi seputar kegiatan posyandu, feature ini juga bisa menampilkan data pangan yangdihasilkan oleh warga RW 06 Cikutra. Selain itu website ini menjadi informasi perihal kekuatan dan kekurangan pangan bagi warga agar bisa saling berbagi.

Kendala yang dihadapi saat melakukan uji coba dan penerapan sistem keterbatasan layanan dari Google Sites karena bersifat free, serta warga yang belum terbiasa dengan penggunaan fasilitas elektonik.
\end{abstract}

Kata kunci : Website, Google Sites, Posyandu, Stunting

\begin{abstract}
Paper-based and electronic-based services do have a different impact, apart from providing convenience and speed, electronic services are more popular with the current generation. In RW 06 Cikutra, Bandung, researchers using the Google Sitesplatform created a $R W$ website that accommodates citizen services, including administration, posyandu, siskamling, to IKM.

Specifically for posyandu services, information on food security is listed that can help the community in preventing stunting issues. In addition to providing information about posyandu activities, this feature can also display food data produced by residents of $R W$ 06 Cikutra. In addition, this website provides information about the strength and lack of food for residents to share with each other.

Obstacles encountered when conducting trials and implementing the service limitation system from Google Sites because it is free, as well as residents who are not familiar with the use of electronic facilities.

Keywords : Website, Google Sites, Posyandu, Stunting
\end{abstract}

\section{PENDAHULUAN}

Merabaknya pandemic Covid-19 di masyarakat membuat berbagai proses pelayanan jasa, produk dan usaha menjadi terhenti. Hal ini disebabkan oleh karena tingkat bahaya penyebaran virus ini yang mengakibatkan kematian. Penerapan prosedur yang ketat diberlakukan pemerintah guna mengurangi penyebaran covid-19, antara lain menjaga jarak, mencuci tangan, serta pembatasan jumlah orang berkumpul bersama yang dibatasi jarak.

Sisi lain kebutuhan makanan warga tidak bisa dipungkiri harus melalui interaksi tetap menjadi prioritas dalam kehidupan, terlebih lagi bagi bayi dan balita yang memerlukan perhatian nutrisi yang baik agar bisa tumbuh kembang dan terhindar dari stunting. Stunting merupakan kekurangan gizi pada bayi dan balita yang bisa mengakibatkan pertumbuhan yang tidak ideal bahkan menjadi mudah terserang penyakit[7],[8],[9],[10].

Oleh sebab itu, peneliti dengan menggunakan feature dari Google (Google Sites) [5],[6], membuat website layanan warga di RW 06 Cikutra, dengan salah satu feature-nya "Posyandu RW-ku", dengan harapan para orang tua bisa memantau pertumbuhan dan perkebangan bayi secara langsung. Serta mengetahui kebutuhan gizi yang diperlukan oleh bayi dan balita agar terhindar dari stunting.

\section{TINJAUAN PUSTAKA}

\section{Website}

Website adalah sebuah kumpulan halaman pada suatu domain di internet yang dibuat dengan tujuan tertentu dan saling berhubungan serta dapat diakses secara luas melalui halaman depan (home page) menggunakan sebuah browser menggunakan URL website[4]. Unsur webiste terdiri dari berikut ini :

a. Domain adalah string identifikasi yang mendefinisikan wilayah otonomi administratif, otoritas atau kontroldalam InternetHosting.

b. Hosting Internet adalah layanan yang menjalankan server yang terhubung ke Internet, memungkinkan organisasi dan individu untuk melayani konten atau layanan host yang terhubung ke Internet.

c. Server adalah bagian dari perangkat keras atau perangkat lunak komputer (program komputer) yang menyediakan fungsionalitas untuk program atau perangkat lain, yang disebut "klien". Arsitektur ini disebut 
model client-server. Server dapat menyediakan berbagai fungsi, sering disebut "layanan", seperti berbagi data atau sumber daya di antara banyak klien, atau melakukan komputasi untuk klien. Satu server dapat melayani banyak klien, dan satu klien dapat menggunakan beberapa server.

2. Posyandu

Posyandu merupakan salah satu bentuk Upaya Kesehatan Berbasis Masyarakat (UKBM) yang dikelola dan diselenggarakan dari, oleh, untuk dan bersama masyarakat dalam penyelenggaraan pembangunan kesehatan guna memberdayakan masyarakat dan memberikan kemudahan kepada masyarakat dalam memperoleh pelayanan kesehatan dasar/sosial dasar untuk mempercepat penurunan Angka Kematian Ibu dan Angka Kematian Bayi[11].

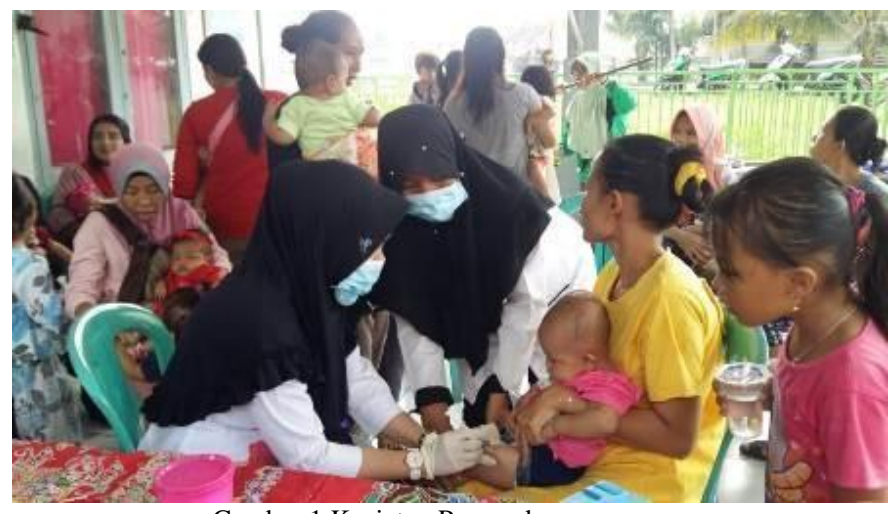

Gambar 1 Kegiatan Posyandu

Sumber : (http://harianmuba.com/2019/06/14/melihat-kegiatan-posyandu-bulanan-partisipasi-dan-tingkat-kehadiran- masyarakat-cukup-tinggi/)

Posyandu merupakan wadah pemberdayaan masyarakat yang dibentuk melalui musyawarah mufakat di desa/kelurahan dan dikelola oleh Pengelola Posyandu, yang dikukuhkan dengan keputusan kepala desa/lurah. Strata Posyandu terbagi menjadi beberapa tingkatan sebagai berikut :
a. Posyandu Pratama
b. Posyandu Madya
c. Posyandu Purnama
d. Posyandu Mandiri

\section{Stunting}

Stunting adalah masalah kurang gizi kronis yang disebabkan oleh kurangnya asupan gizi dalam waktu yang cukup lama, sehingga mengakibatkan gangguan pertumbuhan pada anak yakni tinggi badan anak lebih rendah atau pendek (kerdil) dari standar usianya[12].

Kondisi tubuh anak yang pendek seringkali dikatakan sebagai faktor keturunan (genetik) dari kedua orang tuanya, sehingga masyarakat banyak yang hanya menerima tanpa berbuat apa-apa untuk mencegahnya. Genetika merupakan faktor determinan kesehatan yang paling kecil pengaruhnya bila dibandingkan dengan faktor perilaku, lingkungan (sosial,ekonomi, budaya, politik), dan pelayanan kesehatan. Dengan kata lain, stunting merupakan masalah yang sebenarnya bisa dicegah.

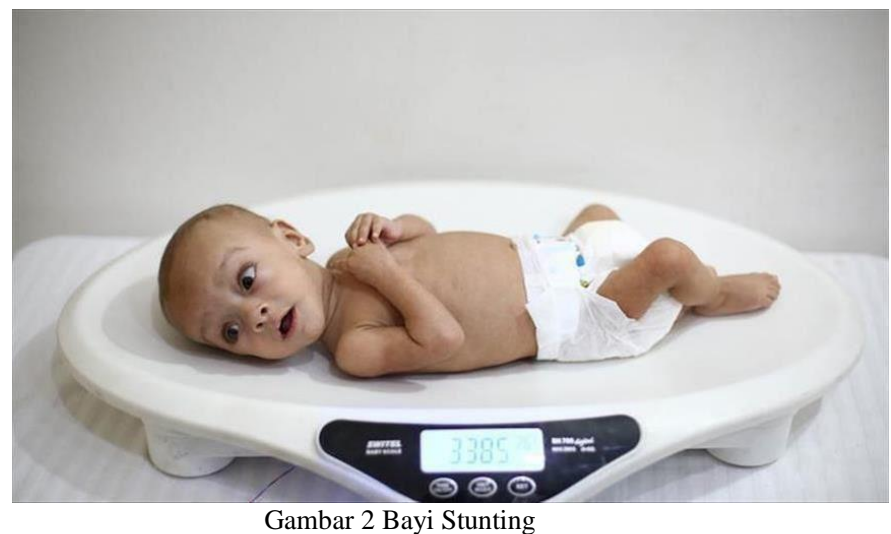

Sumber : (https://www.aa.com.tr/id/dunia/unicef-lebih-dari-7-juta-balita-indonesia-menderita-stunting/1614040) 


\section{ANALISIS DAN PERANCANGAN}

\section{Analisis Masalah}

Berdasarkan paparan yang telah disampaikan pada Bab I, maka dijelaskan bahwa permasalahan yang terjadi di lingkungan RW 06 adalah belum terintegrasinya kegiatan posyandu dengan dukungan sistem, sehingga kegiatan masih bersifat tradisional melibatkan kertas dan konsultasi secara langsung.

Pemantauan kesehatan anak dilakukan oleh petugas saat pelaksanaan jadwal posyandu, yang tentunya hanya bisa dilakukan pada jadwal tertentu saja. Ditambah lagi dengan kurannya pemahaman warga terhadap isu stunting yang berbahaya bagi pertumbuhan bayi dan balita.

\section{Perancangan}

Dari hasil analisis permasalahan di lingkungan RW 06 Cikutra seperti tersebut, maka dirumuskan desain solusi sistem (website) yang akan dibangun sebagai berikut :

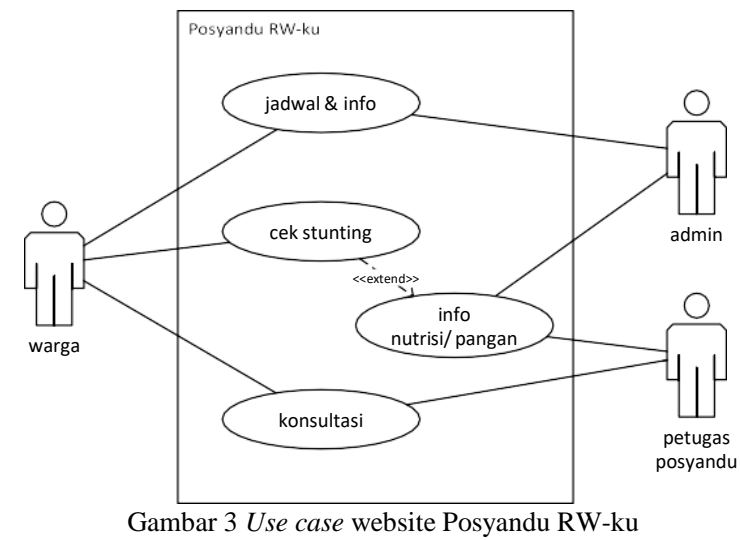

Dari perancangan sistem pada gambar 3 berikutnya digambarkan alur penentuan/ pendeteksian bayi atau balita stunting agar bisa dicegah, seperti terlihat pada gambar 4 berikut ini :

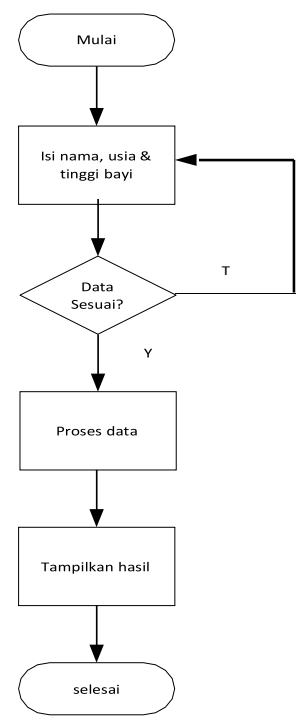

Gambar 4 Flowchart deteksi stunting

Perancangan tersebut kemudian dikembangkan menjadi sebuah website yang menggunakan layanan Google site,dengan tampilan seperti terlihat pada 5 berikut ini :

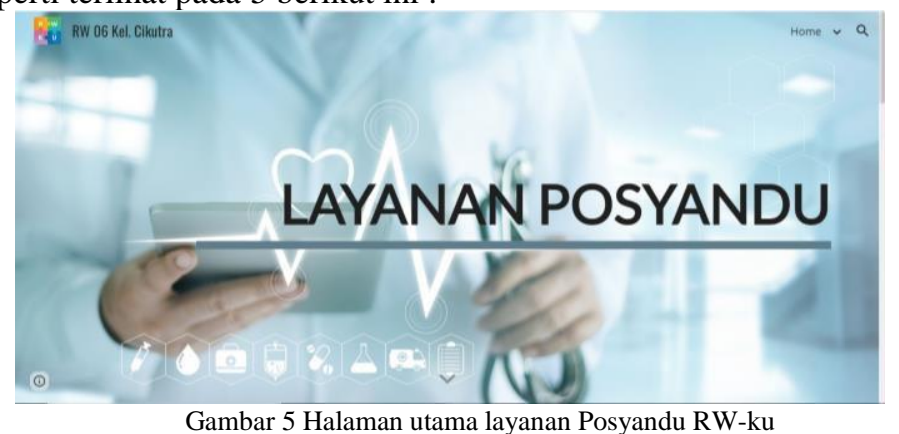


Selanjutnya pada gambar 6 diperlihatkan tampilan untuk halaman yang memuat informasi dan jadwal pelayanan posyandu bagi yang sudah daftar. Dan gambar 7 memperlihatkan info bagi para ibu dan hasil perhitugan/ pendeteksian yang dilakukan, seperti terlihat berikut ini :

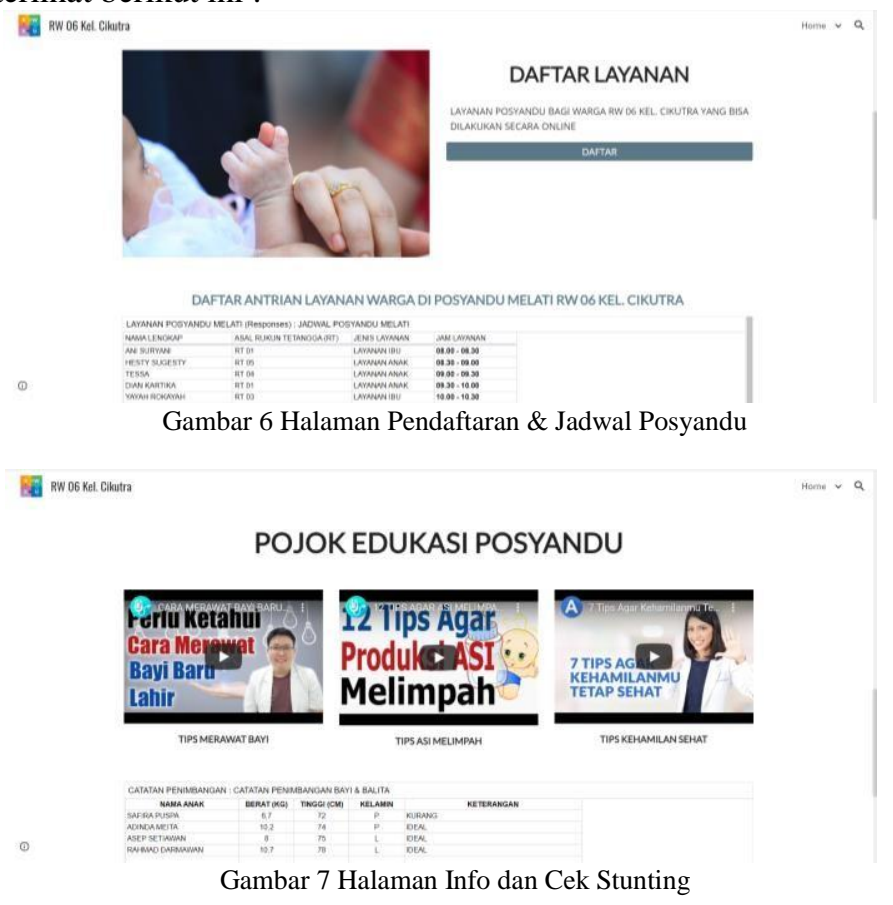

\section{KESIMPULAN}

Dari hasil penelitian yang telah dilakukan di RW 06 Cikutra tersebut maka peneliti bisa menarik kesimpulan bahwa dengan hadirnya website RW 06 membantu warga dalam memperoleh layanan dari perangkat RT dan RW lebih cepat dan mudah. Setiap ibu bayi dan balita bisa melakukan monitoring kesehatan anaknya secara mandiri dengan adanya layanan website posyandu RW-ku. Selain itu, ibu bayi dan balita bisa memonitor kebutuhan pangan, bisa bekomunikasi (memesan) serta mengetahui stok dan lokasinya.

Pengembangan sistem berikutnya bisa dengan menggunakan platform lain, seperti mobile untuk lebih mempermudah aksesnya, tentunya dengan tampilan yang lebih menarik dan feature yang lebih baik sesuai dengan kebutuhan.

\section{REFERENSI}

[1] Kristine H. Luce, Andrew J. Winzelberg, Smita Das, et all, "Reliability of self-report: paper versus online administration", Computers in Human Behavior, Volume 23, Issue 3, May 2007, Pages 1384-1389

[2] Richard Norman, Madeleine T. King, Dushyant Clarke, et all; "Does mode of administration matter? Comparison of online and face-to-face administration of a time trade-off task", Published: 22 February 2010, Quality of Life Research 19, 499-508 (2010)

[3] Juliana A. D. Bonini, Campos, Miriane Lucindo, Zucoloto, et all; "Reliability and validity of self-reported burnout in college students: A cross randomized comparison of paper-and-pencil vs. online administration" Computers in Human Behavior, Volume 27, Issue 5, September 2011, Pages $1875-1883$

[4] Niels Brügger, "Website history and the website as an object of study"; February 2009New Media \& Society 11(1-2):115-132, DOI:10.1177/14614448808099574

[5] Clara Coutinho, University of Minho Braga Portugal, Portugal "Using Blogs, Podcasts and Google Sites as EducationalTools in a Teacher Education Program", https://www.learntechlib.org/p/32834/

[6] Google Sites: Build \& Host Business Websites | Google Workspace, https://workspace.google.com/intl/en_id/products/sites/?utm_source=google\&utm_medium=cpc\&utm_campaign=1009882-WorkspaceAPAC-ID-e $\%$ E2\%80\%A6

[7] Nandita Perumal, Diego G Bassani, et all; "Use and Misuse of Stunting as a Measure of Child Health”; The Journal of Nutrition, Volume 148, Issue 3, March 2018, Pages 311-315, https://doi.org/10.1093/jn/nxx064, Published: 12 March 2018

[8] B Teshome, W Kogi-Makau, et all; "Magnitude and determinants of stunting in children underfive years of age in food surplus region of Ethiopia: The case of West Gojam Zone", Ethiopian Journal of Health Development, DOI: 10.4314/ejhd.v23i2.53223

[9] David Pelletier, Rukhsana Haider, et all; Satyajit Sarkar "The principles and practices of nutrition advocacy: evidence, experience and the way forward for stuntingreduction"; Maternal \& Child Nutrition / Volume 9, Issue S2 / p. 83-100

[10] Lisa A. Sutherland PhD, Barbara Wildemuth PhD, et all; "Unraveling the Web: An Evaluation of the Content Quality, Usability, and Readabilityof Nutrition Web Sites"; Journal of Nutrition Education and Behavior; Volume 37, Issue 6; November-December 2005; Pages 300305

[11] https://dinkes.acehprov.go.id/news/read/2020/01/09/109/apa-itu-posyandu.html

[12] http://dinkes.karanganyarkab.go.id/?p=3713 